Jefferson, M. \& Rosenthal, F.D. (1959) Spontaneous necrosis in pituitary tumour. Lancet, i, 342.

Kirshbaum, J.D. \& Chapman, B.M. (1948) Subarachnoid hemorrhage secondary to a tumor of the hypophysis with acromegaly. Annals of Internal Medicine, 29, 536.

LOPEZ, I.A. (1970) Pituitary apoplexy. Journal of the Oslo City Hospital, $20,17$.

Meadows, S.P. (1968) Unusual clinical features and modes of presentation in pituitary adenoma, including pituitary apoplexy. In: Neuro-ophthalmology, Vol. IV. Symposium of the University of Miami and the Bascom Palmer Eye Institute. C.V. Mosby, St Louis.
MonRo, J.D.R. (1913) A case of sudden death; tumour of pituitary body. Lancet, ii, 1539.

Nurnberger, J.I. \& Korey, S.R. (1953) Pituitary Chromophobe Adenomas. Springer, New York.

Pearce, J.M.S., Swanson, I., Balla, J.I. \& Foster, J.B. (1964) Meningism and pituitary coma. Postgraduate Medical Journal, 40, 610.

Vailati, G., Dawley, J.A. \& Evans, P. (1970) Monocular blindness in a case of pituitary apoplexy. Acta neurologica, 25, 275.

\title{
Pleural effusions and yellow nails of late onset
}

\author{
H. D. Eastwood \\ M.B., M.R.C.P.
}

\author{
T. J. WiLliamS \\ M.B., B.Ch.
}

\section{Department of Geriatric Medicine, Southampton General Hospital}

\begin{abstract}
Summary
Recurrent pleural effusions have recently been described associated with a generalized deficiency of lymphatic drainage. A case is reported which is of interest as, though evidence of such a deficiency had been present as lymphoedema of the legs since childhood, further manifestations of this in the form of discoloured nails and recurrent pleural effusions developed in the eighth and ninth decades.
\end{abstract}

\section{Case report}

In 1962, at the age of 78, a lady was referred to the dermatological out-patients with discoloured finger nails which had been present for the preceding 6 months. The condition has persisted since then, with the principal abnormalities affecting the index fingers. The nails of these fingers showed yellowishgreen discolouration, transverse ridging and excessive side-to-side curvature. The other finger nails were affected to a lesser extent. At that time, she was otherwise well, apart from oedema of both ankles which had been present since childhood.

Subsequently, she had several admissions to hospital with episodes of acute bronchitis and broncho-pneumonia. In 1968, she was admitted with bronchitis and was found to have bilateral pleural effusions. These were drained and did not immediately recur. Two years later, however, she was readmitted with shortness of breath and found to have developed further effusions which also appeared to have followed an episode of bronchitis. No other cause for the effusions was found and they were again successfully treated by aspiration. In November 1971, she was again admitted with progressive dyspnoea, associated with a fortnight's cough and the expectoration of greenish sputum.

On examination, she was an alert 87-year-old dyspnoeic at rest but not cyanosed. She was nof clinically anaemic and there was no evidence of skin rash, nor of an arthritis. The nail changes? already described were again noted. Clubbing was not present. Her pulse was regular, $74 / \mathrm{min}$, BP $140 / 80 \mathrm{mmHg}$. The ankle oedema noted previously was present but there was no other evidence of congestive heart failure. The JVP was not raised and there was neither hepatomegaly nor ascites. The apex beat was not palpable. The heart sounds were normal. There was evidence of large bilateral pleural effusions. The rest of the findings on examination were normal for a woman of her age.

\section{Investigation}

Hb $14.3 \mathrm{~g} / 100 \mathrm{ml}$; WBC $5900 / \mathrm{mm}^{3}$; ESR $30 \mathrm{~mm} /$ $1 \mathrm{hr}$; blood urea $34 \mathrm{mg} / 100 \mathrm{ml}$ with normal electrolytes. There was no proteinuria. Plasma proteins $6.9 \mathrm{~g} / 100 \mathrm{ml}$; albumin $4.4 \mathrm{~g} / 100 \mathrm{ml}$; globulin $2.5 \mathrm{~g} /$ $100 \mathrm{ml}$. The anti-nuclear factor (ANF) test was negative and her protein-bound iodine was normal at $6.2 \mu \mathrm{g} / 100 \mathrm{ml}$. The ECG showed sinus rhythm with occasional ventricular ectopic beats with complexes of low voltage. The chest X-ray after aspiration showed no evidence of an underlying lung lesion, though the heart size was slightly increased.

Gynaecological examination excluded an ovarian lesion.

The effusions were again aspirated and strawcoloured fluid with a protein content of $4.8 \mathrm{~g} / 100 \mathrm{ml}$ obtained. A similarly high protein content had been 
present in previous aspirates. No organisms were cultured from the fluid. In particular, there was no evidence of tubercle bacilli which had also been looked for on several previous occasions. The predominant cell type was lymphocytic and no malignant cells were found. A pleural biopsy was obtained at the time of aspiration with normal findings.

In view of the fact that the yellow discoloured nails and the longstanding oedema of the legs, suggested an abnormality of the lymphatic system, a lymphangiogram of the left arm was performed. This X-ray confirmed a defect by showing a marked hypoplasia of the lymphatic drainage. A similar hypoplasia of the lung's lymphatic system would account for the effusions following episodes of lung infection.

\section{Discussion}

Discolouration of the nails associated with lymphatic deficiency and lymphoedema was termed the 'yellow nail' syndrome by Samman \& Whyte (1964). They described thirteen cases, the oldest of whom was 65 at the time of presentation, and pointed out the characteristic features of the nails as exhibited in this case. The predominant involvement of the nails of the index finger on both hands is similar to that of the case reported by Dilley et al. (1968). This distribution is unexplained.

The further association of pleural effusions complicating the lymphoedema and yellow nails was described by Emerson (1966) and since then reported in such cases as that of D'Souza (1970). The theory of the development of the effusions is that respiratory infections may damage a previously adequate but hypoplastic lymphatic drainage system of the lung, so that it is no longer able to deal with the increased load following further incidents. In the limbs, it is known that persistent lymphoedema may develop following an infection or other episode which overloads a hypoplastic system which hiterto had been able to function adequately.

In a recent review of pulmonary manifestations of the yellow nail syndrome by Hiller, Rosenow \& Olsen (1972), the oldest case reported was a patient of 71 who had had chronic oedema of his lower extremities for 4-5 years, and yellow nails for 2 years before presenting with respiratory symptoms associated with a pleural effusion. The interest in this present case is in the even later age that the yellow nails developed, and the fact that it was not until the ninth decade that pleural effusions developed despite evidence to suggest lifelong lymphatic hypoplasia in the persistence of chronic oedema of the legs since childhood.

\section{Acknowledgments}

We are grateful to Dr F. Ashton for permission to publish details of this case and Dr M. W. Stannard for performing the lymphangiogram.

\section{References}

Dilley, J.J., Kierland, R.R., Randall, R.V. \& Shick, R.H. (1968) Primary lymphoedema associated with yellow nails and pleural effusions. Journal of the American Medical Assoctation, 204, 670.

D'SouzA, M.F. (1970) Generalized lymphoedema with yellow nails, pleural effusions and macroglobulinaemia. Proceedings of the Royal Society of Medicine, 63, 456.

EMERSON, P.A. (1966) Yellow nails, lymphoedema and pleural effusions. Thorax, 21, 247.

Hiller, E., Rosenow, E.C. \& Olsen, A.M. (1972) Pulmonary. manifestations of the yellow nail syndrome. Chest, 61, 452

Samman, P.D. \& White, W.F. (1964) The 'yellow nail' syndrome. British Journal of Dermatology, 76, 153.

Postgraduate Medical Journal (May 1973) 49, 365-367.

\section{The use of intra-arterial Urokinase in a case of recurrent arterial occlusion}

\author{
B. J. BOUCHER \\ M.D., M.R.C.P.
}

\author{
E. M. CONNOLLY \\ M.B., B.Ch., B.A.O.
}

\section{S. C. FARROW \\ M.A., M.R.C.P.(U.K.) \\ Departments of Medicine and Pathology, London Hospital E.1}

\section{Summary}

The present case report describes the use of intraarterial Urokinase in an occlusive episode involving the right radial and ulnar arteries. Details of the case history are given and the choice of thrombolytic therapy, plus its route of administration are discussed.

\section{Introduction}

The use of intravenous lytic therapeutic agents has been well defined in the treatment of occlusive venous thrombosis (Kakkar et al., 1969; Robertson, Nilsson \& Nylander, 1969), although there is no ideal regime for their use (Study Group, 1970). Streptokinase has been widely used in episodes of acute arterial thrombo-occlusive disease (Polidwoda et al., 1969; Martin, Schoop \& Zeitler, 1970; Amery et al., 1970) and occasionally it has been given intraarterially by local perfusion (McNicol et al., 1963; 